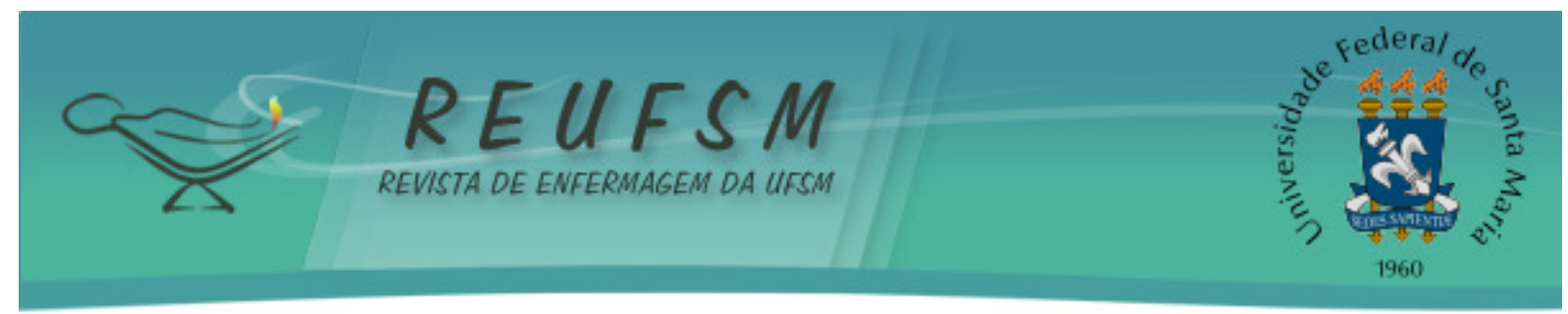

ARTIGO ORIGINAL

\title{
EXPERIÊNCIAS E ESPECIFICIDADES DA VIOLÊNCIA ESCOLAR NA PERCEPÇÃO DE FUNCIONÁRIOS DE UMA ESCOLA PÚBLICA
}

\section{EXPERIENCES AND SPECIFICITIES OF SCHOOL VIOLENCE IN THE PERCEPTION OF EMPLOYEES OF A PUBLIC SCHOOL}

\section{EXPERIENCIAS Y ESPECIFICIDADES DE LA VIOLENCIA ESCOLAR EN LA PERCEPCIÓN DE LOS EMPLEADOS DE UNA ESCUELA PÚBLICA}

\author{
Luciana Netto ${ }^{1}$ \\ Rayssa Nogueira Rodrigues ${ }^{2}$ \\ Mariana Aparecida Costa ${ }^{3}$ \\ Jaqueline dos Santos ${ }^{4}$ \\ Gabriel Alves Tatagiba ${ }^{5}$
}

RESUMO: Objetivo: compreender a experiência e especificidades dos episódios de violência na escola, frente à declaração de funcionários de uma escola do município de Divinópolis-MG. Método: utilizou-se o método qualitativo, sendo os dados coletados por meio de entrevistas com roteiro semiestruturado. Os dados foram avaliados por meio da análise de conteúdo. Resultados: para os funcionários, a instituição de ensino está à sujeição de uma desordem que vem difundindo e tornando a fragilidade sua personagem principal. Envolvendo toda a equipe escolar, a violência adentra na qualidade do serviço destes, com efeitos em suas histórias de violência como testemunhas, vítimas e/ou ouvintes. Considerações Finais: a pesquisa mostra que a violência tem origens multifatoriais. $O$ foco dessas intervenções compreende redução do comportamento inadequado dos estudantes e habilitação/fortalecimento do comportamento dos funcionários e demais membros do ambiente escolar.

Descritores: Violência; Comportamento do adolescente; Instituições acadêmicas.

ABSTRACT: Objective: to understand the experience and specificities episodes of violence at school, regarding the statement of employees of a school in the town of Divinópolis-MG. Method: we used the qualitative method, and the data collected through semi-structured interviews. Data were analyzed by content analysis. Results: for the staff, the educational institution is the subjection of a disorder that has been disseminating and making his main character weakness. Involving all school staff, violence enters the quality of service thereof, with effects on their stories of violence as witnesses, victims and / or listeners. Conclusion: the study shows that violence has multifactorial origins. The focus of these interventions includes reducing the inappropriate behavior of students and enable / strengthening of the behavior of employees and other member of the school environment.

Descriptors: Violence; Adolescent behavior; Schools.

RESUMEN: Objetivo: conocer la experiencia y especificidades de los episodios de violencia en la escuela, frente a la declaración de los empleados de una escuela en el municipio de

\footnotetext{
${ }^{1}$ Enfermeira. Doutoranda em Enfermagem pela Universidade Federal de Minas Gerais. Professora Assistente II da Universidade Federal de São João del-Rei. E-mail: luciananetto@ufsj.edu.br

${ }^{2}$ Graduanda em Enfermagem pela Universidade Federal de São João Del Rei. E-mail: rayssa_nr@yahoo.com.br ${ }^{3}$ Graduanda em Enfermagem pela Universidade Federal de São João Del Rei. PIIC (FAPEMIG/UFSJ). E-mail: maricosta.ufsj@yahoo.com.br

${ }^{4}$ Discente do Ensino Médio. Bolsista da FAPEMIG - PIBIC Júnior. E-mail: jakel08@hotmail.com

${ }^{5}$ Discente do Ensino Médio. Bolsista da FAPEMIG - PIBIC Júnior. E-mail: gabrieltatagiba99@yahoo.com.br
} 


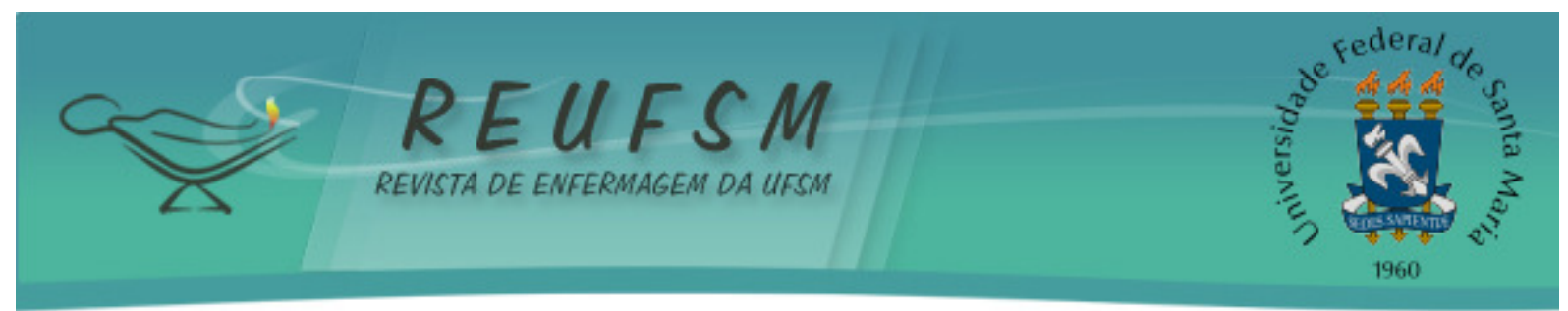

Divinópolis-MG. Metodología: se utilizó el método cualitativo, y los datos fueron recogidos a través de entrevistas semiestructuradas. Los datos fueron analizados por análisis de contenido. Resultados: para los empleados, la institución educativa está sujeta a una desorden que viene difundiendo y haciendo su debilidad su carácter principal. Involucrando todo el personal de la escuela, la violencia entra en la calidad de sus servicios, con efectos en sus historias de violencia como testigos, víctimas y / $u$ oyentes. Conclusión: el estudio muestra que la violencia tiene orígenes multifactoriales. El objetivo de estas intervenciones incluyen la reducción de la conducta inapropiada de los estudiantes y habilitación / reforzamiento de la conducta de los empleados y otros miembros del entorno escolar.

Descriptores: Violencia; Conducta del adolescente; Instituciones académicas.

\section{INTRODUÇÃO}

A violência na adolescência manifesta-se de diversas formas, tanto que a presença de um indício físico ou sintoma isolado, não configura sua ocorrência. Evidências sutis podem referir à abstenção emocional, nutricional e abuso, manifestas por efetiva passividade e silêncio, tendência ao isolamento, comportamento retraído, agressivo ou mesmo a presença de marcas corporais. Portanto, o atendimento multiprofissional qualificado, integrado, humanizado e holístico são ferramentas imprescindíveis no que tange a identificação da problemática, seja ela de cunho físico, negligencial, sexual ou emocional. ${ }^{1}$

O fenômeno da violência é hoje um dos mais consideráveis problemas do mundo. Seu movimento em distintas classes sociais e econômicas, além da sua magnitude e gravidade, evoca às autoridades de saúde pública uma melhor compreensão das estratégias de promoção de saúde e prevenção. ${ }^{2}$ A violência se expressa com uma sobrecarga ao adoecimento da população, e não obscuramente leva à mortalidade precoce, em especial de adolescentes.

Para compreender a violência é importante analisar a interface de questões sociais, econômicas e institucionais. ${ }^{3}$ A Organização Mundial da Saúde (OMS) ao referir-se ao tema, adota o significado da assimétrica relação de desigualdade, o que permeia o uso do poder real ou ameaça além do uso da força física, com a possibilidade de resultar em ferimento, prejuízo psicológico, opressão ou morte. ${ }^{4}$

Apesar das diversas nuanças na interpretação do que seja violência, sabe-se que os fatores geográficos, históricos, constituição genética, idade, sexo, dinâmica familiar, entre outros se referem à desordem do comportamento humano. ${ }^{5}$

Quando se trata de violência no contexto escolar, é necessário ainda, enunciar outros determinantes que transcendem os espaços familiares, sociais, culturais, religiosos e de lazer. As características da instituição de ensino também constituem fatores que interferem no comportamento dos adolescentes. As instalações físicas, o espaço geográfico, os recursos humanos e o lendário da instituição são aspectos que se inserem decisivamente nesse cenário. ${ }^{5}$

Não é demais lembrar que a aprendizagem, função precípua da escola, envolve a aquisição de informações, destreza e valores. Todas ocorrem em prol de uma ação educativa avultadas no interior da escola. É evidente que a atuação do professor é destaque nesse contexto, mas as relações no cotidiano escolar ultrapassam o binômio professor-aluno uma vez que outros atores estão envolvidos no processo. Para o alcance dos objetivos educacionais, a atuação do professor é complementada pelos demais trabalhadores em educação não docentes, aqui denominados funcionários da escola. ${ }^{6}$

Atualmente, com o avanço da escolarização, nota-se que, mais do que serem ensinadas por professores, as pessoas necessitam serem instruídas por educadores, entendendo-se que 


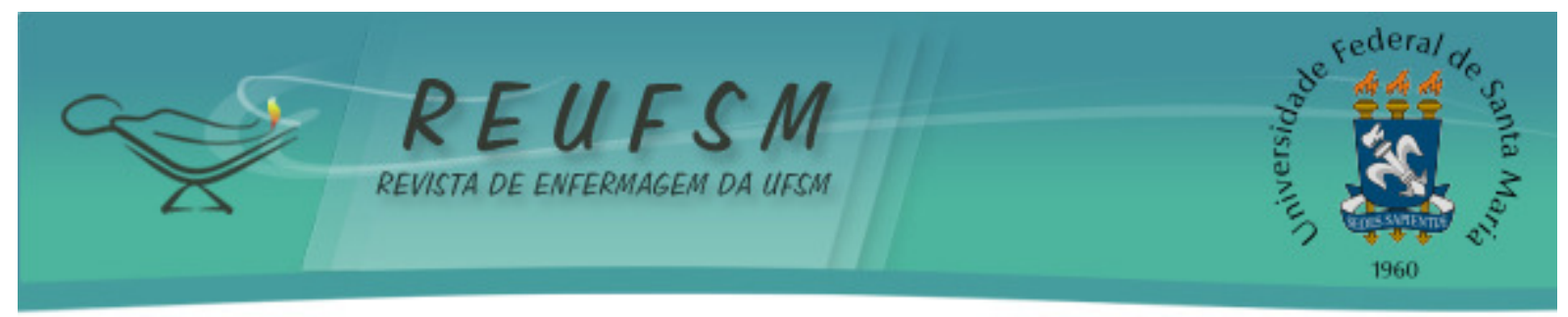

todos os que têm presença constante no ambiente escolar podem desempenhar esse papel, são educadores em potencial, independentemente da função que exercem. ${ }^{6}$

Assim, implicações dessa concepção evidenciam que, merendeiras cuidam da educação alimentar, bibliotecários auxiliam no hábito da leitura, faxineiros ficam atentos à higiene do ambiente, secretários e diretores contribuem com o processo administrativo enfim, esses e outros funcionários presentes e atuantes na escola tornam-se tão imprescindíveis quanto os professores. ${ }^{6}$

Considerando esses profissionais, é importante ressaltar que quando se discute a esfera escolar, a indisciplina manifesta pelos xingamentos, desobediência, ofensas e discussões não configuram uma característica presente somente na relação entre professor e aluno. 0 relacionamento negativo estabelecido entre funcionários e alunos, sejam eles secretários, bibliotecários, serventes, inspetores também pode ser corriqueiro e, por vezes, banalizado.

Esses funcionários possuem funções dentro da instituição, porém pouco reconhecidas, muito pelo fato de estarem subordinados a uma direção, pelo restrito contato com os alunos e ainda por auxiliarem na imposição de normas. Quando os alunos rompem regras, os funcionários são os indivíduos que tentam coibir a indisciplina na busca do controle do espaço escolar. Essa condição os torna vulneráveis a relação conflituosa, principalmente com alunos, pois é comum a discordância daquilo que é imputado e estes acabam por afrontar os funcionários. ${ }^{7}$

Diante do envolvimento de inúmeros fatores que contribuem para a presença da violência no ambiente escolar, professores, alunos e funcionários queixam-se do cenário atual. Esta condição permeia estratégias de disciplina punitiva ou repressiva, porém, essas medidas acionadas pela escola não surtem mais efeito. $\mathrm{Na}$ verdade, são congêneres àquelas que contribuem para a conduta agressiva em casa. Portanto, esse tipo de advertência ou mesmo as suspensões já se tornaram atitudes retrógradas e com consequências inconsistentes. ${ }^{8-9}$

Frente ao envolvimento de inúmeras esferas, é relevante ostentar que apoio e orientação aos adolescentes configuram a principal perspectiva do alcance de um compromisso para enfrentamento dessa situação. Um estudo internacional que descreve a avaliação de oficinas destinadas a professores, demonstrou resultados efetivos destas oficinas na habilidade destes profissionais em lidar com problemas de comportamento de crianças em sala de aula. ${ }^{9}$

Sabe-se ainda que para promover condições indispensáveis para operacionalização de medidas destinadas a conter e mesmo prevenir a violência na escola requer mobilização política; fortalecimento de ações no serviço de saúde com assistência psicológica, social, à lesão e legal; além de práticas educativas estabelecidas no convívio familiar e social. ${ }^{9}$ Nesse sentido, destaca-se a iniciativa dos ministérios da Saúde e Educação em que implementaram, em 2008, o Programa Saúde na Escola (PSE), contribuindo para o fortalecimento de ações na perspectiva do desenvolvimento integral e proporcionando à comunidade sua participação em programas e projetos que articulem saúde e educação. 0 PSE foi desenvolvido no intuito de enfrentar as vulnerabilidades que comprometem o pleno desenvolvimento de crianças e adolescentes brasileiros, constituindo assim em iniciativa de impacto positivo sobre a qualidade de vida de educandos e educadores. Engajados na construção de uma cultura de paz nas escolas, as ações são estruturadas em quatro blocos, com destaque para o segundo bloco que enfatiza as estratégias de promoção de saúde e combate às diferentes expressões de violência, consumo de álcool, tabaco e outras drogas. ${ }^{10}$

Em uma revisão recente de estudos nacionais sobre intervenções realizadas no contexto escolar foi evidenciado raros trabalhos conduzidos por funcionários dirigidos para a prevenção de comportamento agressivos dos adolescentes no ambiente escolar. Em geral, revelam-se intervenções carreadas em sua maioria, por professores. Assim, consolidado o momento de ressignificação do espaço escolar para além das paredes das 


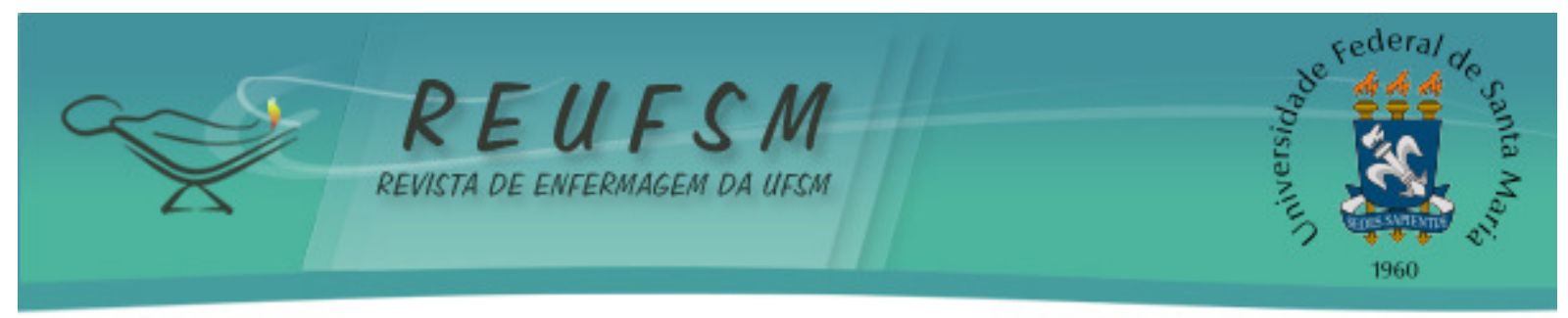

salas de aula e transmissão de conteúdos, entender o atual modelo pedagógico requer a concepção de aprendizagem integrativa e colaborativa, considerando, portanto, todos os integrantes da escola como protagonistas de tal processo. A compreensão desse conceito implica, entre outros aspectos, refletir sobre a nova função social da escola e, por consequência, sobre a nova função pedagógica de seus profissionais.

Diante de tal retrato, o trabalho tem como objetivo compreender a experiência e especificidades dos episódios de violência na escola, frente à declaração de funcionários de uma escola estadual de ensino fundamental e médio do município de Divinópolis-MG, conduzida pela questão norteadora: "Você já presenciou algum tipo de violência nesta escola? Fale sobre isso".

\section{MÉTODO}

Trata-se de uma pesquisa qualitativa que se fundamenta na abordagem de funcionários de uma escola pública de ensino fundamental e médio de um município da região centro-oeste do Estado de Minas Gerais, Brasil. A população estudada, composta por 10 (dez) sujeitos, sendo $90 \%$ do sexo feminino, $50 \%$ com residência no bairro da instituição e os demais em bairros próximos; $50 \%$ trabalham no turno da manhã, $20 \%$ a tarde e $30 \%$ a noite com predomínio do vínculo empregatício único, com tempo médio de serviço de 13 (treze) anos.

Os sujeitos foram contatados quanto à disponibilidade e interesse, sendo agendadas entrevistas, que foram realizadas individualmente, na própria escola. Precedendo a coleta de dados, obteve o Consentimento Livre e Esclarecido dos informantes, bem como o consentimento formal da instituição pedagógica.

Este trabalho foi apreciado e aprovado pelo Comitê de Ética em Pesquisa do Hospital São João de Deus - Fundação Geraldo Corrêa sob Parecer №. 115/2011 e pelo Comitê de Etica em Pesquisa Envolvendo Seres Humanos do Campus Centro-Oeste da UFSJ (CEPES/CCO) sob Parecer $\mathrm{N}^{\circ}$. 016/2011, sendo conduzido de acordo com os padrões éticos exigidos.

0 roteiro contemplava inquisições de perguntas diretas conduzido pela questão norteadora: "Você já presenciou algum tipo de violência nesta escola? Fale sobre isso". Os nomes verdadeiros dos entrevistados foram substituídos e identificados com a letra $F$ (funcionário), seguida do número que correspondia à ordem da entrevista, determinada aleatoriamente, a fim de garantir o anonimato.

O parâmetro para encerramento das entrevistas foi o critério da saturação, ou seja, quando as informações fornecidas pelos participantes da pesquisa pouco acrescentavam ao material obtido. ${ }^{11}$

As entrevistas foram gravadas e posteriormente transcritas. Procedeu-se com a análise do conteúdo dos depoimentos, seguido de um desmembramento do texto em unidade de registro, que constava fielmente as falas dos sujeitos; e unidade de significado que retratava as consequências que os atos violentos produziam. Por fim, a construção categorial "testemunho e apreciação da violência escolar" se deu a partir da emersão das falas dos sujeitos que versava a experiência e as especificidades dos episódios de violência escolar. ${ }^{12}$

\section{RESULTADOS E DISCUSSÃO}

A proposta do trabalho que pressupunha apresentar e discutir as experiências e especificidades da violência no ambiente escolar foi além, pois, em algum momento da entrevista, os pesquisados retratavam ações que interferiam na geração do que hoje é considerado um problema de saúde pública, além de mencionar medidas que contribuiriam para redução desses episódios. Não obscuramente as falas discorriam da importância da luta pelo fortalecimento das equipes multiprofissionais, com revigoramento da assistência 


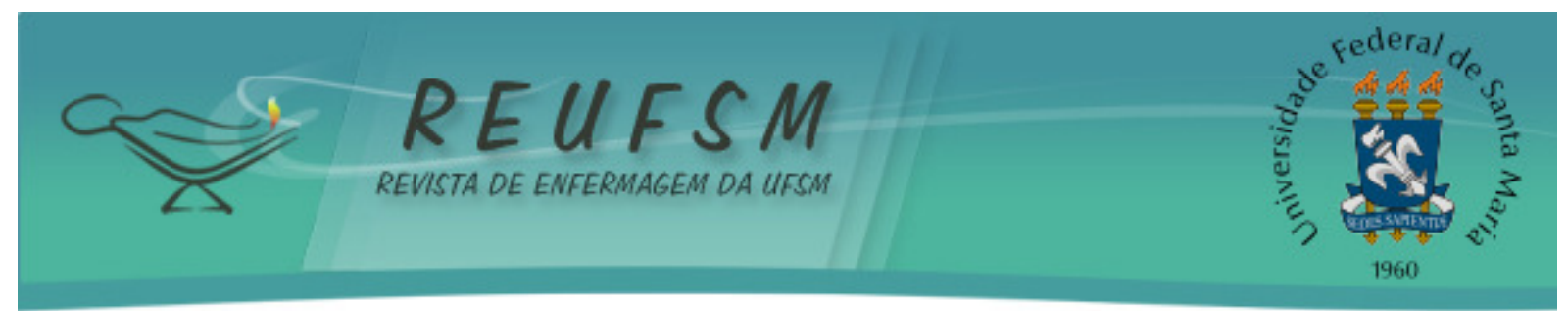

psicológica, social; revisão de políticas públicas; estimulação aos pais a proporcionarem proteção e afeto aos filhos; atividades lúdicas cooperativas com os alunos que requeiram a ajuda de outros colegas, dentre outras.

Observa-se que o fenômeno violência escolar não foi, portanto, dissociado da violência que ocorre na sociedade. A mentalidade de que a escola se instaurou como instância do poder não fez parte dos apontamentos dos entrevistados, uma ocupação presente por anos em sua trajetória. ${ }^{13} 0$ pensamento que agora vigora, é que a instituição de ensino está a mercê de uma desorganização que vem se propagando e tornando a fragilidade sua personagem principal. De maneira específica, no que tange a violência psicológica, as carências afetivas, condições sociais e econômicas foram os principais enfoques dos entrevistados que remetiam a presença e persistência deste efeito deletério no contexto escolar. ${ }^{13}$

A análise não explorou os espaços da instituição nas quais a violência ocorre com maior frequência, mas o presente estudo evidenciou que as altercações fazem parte de um painel em que não incluem somente os professores, mas toda a equipe envolvida no trabalho escolar. As falas retratam que todos os funcionários entrevistados já se envolveram em algum momento como vítimas, ouvintes ou testemunhas, mas não como agressores. $\mathrm{E}$ o que preserva na singularidade das falas é a presença de um sentimento de revolta e/ou emoção seja presenciando os alunos como sujeitos passivos ou ativos de tal situação. ${ }^{7}$

[...] um aluno foi ajudar um serviçal a levar uma bandeja e a outra cantineira agrediu verbalmente o aluno. (F2)

[...] eu achei assim muito triste, sabe?! Eu não gostei dessa situação. (F2)

[...] É frequente que às vezes os alunos deixam os pratos aqui no pátio da escola né [...] a cantineira, por exemplo, vai pedir os alunos e os alunos falam que elas são obrigadas a levar as vasilhas, são essas coisas desagradáveis que acontecem. (F2)

\section{Eles [os alunos] respondem muito a gente. (F7)}

Estes depoimentos recorrem às relações em que se observa, mais do que o desrespeito pelo funcionário, alguns alunos manifestam um sentimento de desprezo pela profissão por eles exercida. 0 trabalho dos funcionários é complicado por estar envolvido com o controle do espaço escolar, implicando assim em um enfrentamento com os alunos. Na maioria das vezes, eles possuem o papel de fiscalizar a "validação" das normas que não necessariamente são acatadas pelos estudantes, gerando, muitas vezes, desavenças e discussões. ${ }^{7}$

A transgressão de boas maneiras e à ordem dos adolescentes, contribuem para que os mesmos busquem em se impor pela força e pela agressão. ${ }^{14}$ Porém, é válido ressaltar que essa conotação depreciativa de rotulações/estereótipos para culpabilizar os adolescentes pelos inúmeros atos violentos dentro do ambiente escolar é errônea. Os resultados do presente estudo remontam a necessidade de intervenções universais com a finalidade de auxiliar na tarefa de prevenir e minimizar comportamentos agressivos no contexto escolar, promovendo principalmente a competência social ${ }^{15}$ uma vez que esta compreende os comportamentos socialmente aceitos que são apreendidos e desempenha papel preponderante no desenvolvimento humano e funcionamento adaptado da escola, afetando as relações com professores, a aceitação pelos pares e a realização acadêmica.

Quanto às sugestões de melhoria, verifica-se que a essência gira em torno da busca por uma instituição que tenha como elemento definidor o desenvolvimento de 


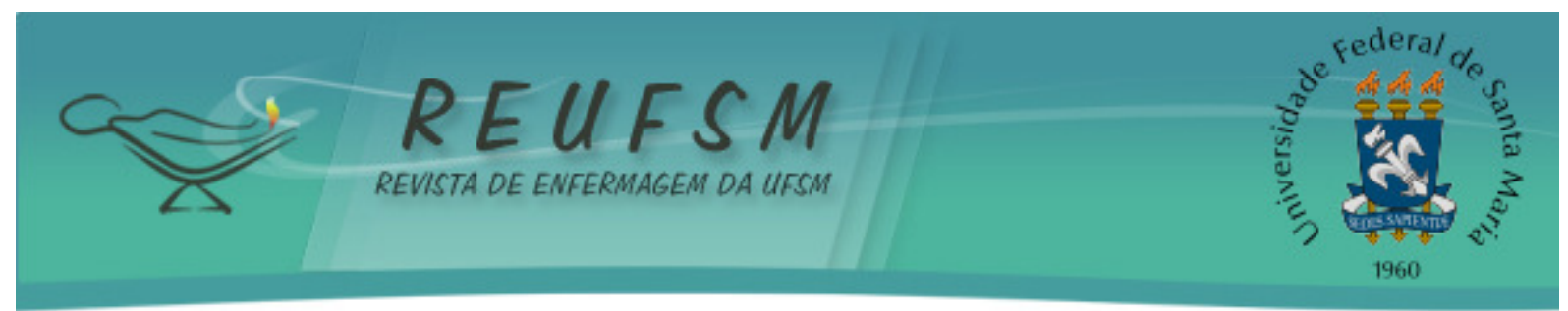

estratégias que façam com que o estudante se sinta integrado à escola e integre os pais e a comunidade no cotidiano escolar ${ }^{7}$, como mostra o que foi proferido durante a discussão:

[...] projeto [...] essas gincanas mesmo que eles participam para que possa né, socializar [...]. (F3)

\section{[...] ter mais a participação dos pais [...]. (F5)}

As discrepâncias internas no sistema educacional podem ser um fator que fomenta a violência nos estabelecimentos de ensino. Escolas difíceis de serem administradas com um olhar desconfiado da sociedade são retratos de um índice elevado de abandono, baixo número de aprovações, com alta taxa de evasão, além de serem detentoras, muitas vezes, de uma grande quantidade de ocorrências por porte de armas. É nesse cenário que ainda estão presentes profissionais despreparados, precária infraestrutura, baixo incentivo governamental, dentre outros. Por este modo de organização e características é que o próprio sistema educacional acaba por ser uma ferramenta de violência. ${ }^{16}$

A escola deve ser um espaço atrativo, onde sejam facultadas atividades que despertem o seu interesse. $O$ alvitre é fazer com que os alunos se sintam mais inteirados à escola por meio de ensejos de lazer, esporte e cultura, bem como por meio de expansão de atividades extra curriculares, o que pode se mostrar como uma forma de encarar a violência na escola. ${ }^{7}$

Foi observado ainda que para os funcionários, a violência está associada à forma como a sociedade se organiza e constrói suas normas e valores. Muitos dos sujeitos atribuíam essa indisciplina dos alunos à dinâmica familiar, a qual na ausência do afeto, supervisão e estabelecimento de regras seria um dos fatores decisivos para se tornarem adolescentes agressivos. ${ }^{17}$

[...] a carência afetiva deles, a falta de toque. Estou com um menino aí que já veio não sei quantas vezes para eu tirar o aparelho dele.

[...] Ele gostou deu puxar a bochecha dele sabe?! (F1)

Corroborando o que foi encontrado neste estudo, autores encontraram em seus resultados de pesquisa que, aliado ao fato de ainda ser aceita a ideia de que os filhos são uma espécie de propriedade dos pais, o que thes dão o direito inclusive de bater, a sociedade como um todo ainda reforça uma concepção arcaica e enraizada culturalmente. $^{18}$ Essa postura tradicional de manter a educação com estratégias incoerentes, com gritos e tapas já não surte mais efeito. Na verdade, é um adicional a imposição de violência que, muitas vezes, é refletida em outros ambientes como o escolar.

[...] primeiro educação dos meninos em casa, porque as mães dão razão para os meninos [...]. (F7)

Não obstante, isso reflete a importância do envolvimento de uma equipe inter e multidisciplinar, pois este cenário configura-se em um fenômeno em rede, onde essas manifestações de hoje estão somente junto ao convívio familiar, futuramente poderão perpetuar para outros meios.

Nota-se ainda, durante análise das falas, que os entrevistados relatavam os comportamentos agressivos dos adolescentes aplicando a estes, significados específicos. Uma classificação que não afasta daquela estabelecida pela OMS, que descreve as consequências que os atos violentos produzem, mencionando a violência física, psicológica, sexual e negligencial. ${ }^{12}$ Contudo, as falas a seguir aludem a violência verbal, uma tipologia que não se aplica a definição da OMS: 


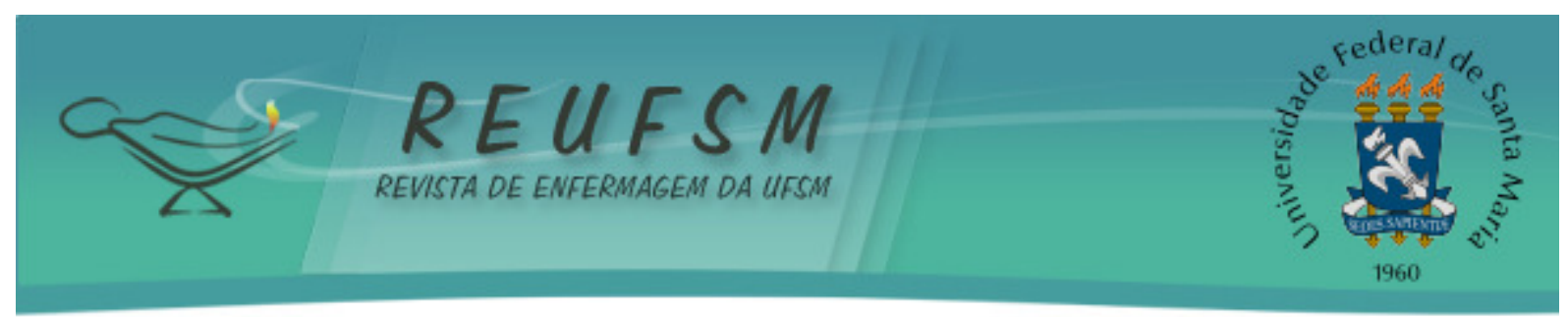

Verbal, muitas vezes. (F1)

$A$ violência mais aqui na escola é só verbalmente mesmo, é difícil um aluno é... atacar, agarrar de pescoção [...]. (F2)

Aqui é só verbal né?! Física aqui eu acho que nunca presenciei. Mais é verbal mesmo... (F3)

O fato de estar presente em diferentes classes sociais e econômicas, somado aos múltiplos enfoques e direcionamentos que podem ser atribuídos, a violência colabora para abordagens ambíguas e/ou múltiplas, e esse fato é observado quando muitos fazem analogias à violência verbal com a psicológica.

Frente a essas diferentes nuances, cabem explicações, pois apesar do ato violento ser único por apresentar motivação, desenlace, dia e particularidades próprias, as características podem ser parecidas. Quando isso ocorre, elas tendem a ser reunidas em categorias, no intuito de construir uma representação em evidência, para com a sociedade, escola e pesquisadores. ${ }^{5}$

Nessa concepção ampla do fenômeno violência, há autores que a consideram em ações que resultam algum prejuízo emocional como ameaça; infamar religião, postura e empenho da pessoa; agressão física contra algum ente querido; gozar da fraqueza para produzir empoderamento e perpetrar o medo, ridicularizar, entre outros. Ou seja, defendendo a violência verbal como incivilidade, ${ }^{7}$ diferentemente da compreensão da OMS, que leva em consideração as consequências que os atos violentos produzem. Para a $\mathrm{OMS}$, esses comportamentos seriam classificados como violência psicológica. ${ }^{19}$

Ainda, ao considerar as falas, poucos entrevistados não relataram o aumento dos eventos de indisciplina, porém todos caracterizaram a violência em detrimento de sua trivial ocorrência. A multiplicidade dos atos violentos presenciados motivaram os funcionários a relatarem a significação física e psicológica.

[...] Muitas vezes parte do professor também, a falta de respeito, muita discriminação. A gente ainda vê, principalmente a... financeira. O professor costuma fazer crítica com aluno mais calmo, mais tranquilo [...]. (F1)

Eu acho que a violência na escola está aumentando. Mais é verbal né?! Com palavrões, até ameaças. (F9)

Em função da frequência com que ocorre, a violência na escola também remonta ao embate funcionário/aluno, sendo essa condição deferida pelos entrevistados, no que tange à dificuldade de assumirem um papel de autoridade dentro da instituição. Os funcionários tornamse, muitas vezes, vítimas de alunos desobedientes e desrespeitosos, pelo fato de terem compromissos e funções para auxiliarem na manutenção, organização da instituição e controle dos alunos. Mas o que se observa, é que a dissonância no sistema educacional pode ter contribuído para a violência nas instituições de ensino, pois na prática a escola tem configurado uma característica de reprodução de desigualdades, opondo sua missão democrática e inclusiva. ${ }^{7}$ Uma ocorrência não pontual e que é vista ao explorar a situação da escola na sociedade contemporânea como um todo, é que há desarmonia entre a instituição de ensino e aquilo que socialmente dela se espera.

Perante o exposto, a escola que é considerada, portanto, como responsável pela educação e proteção dos estudantes, acaba por envolver-se em práticas excludentes e 


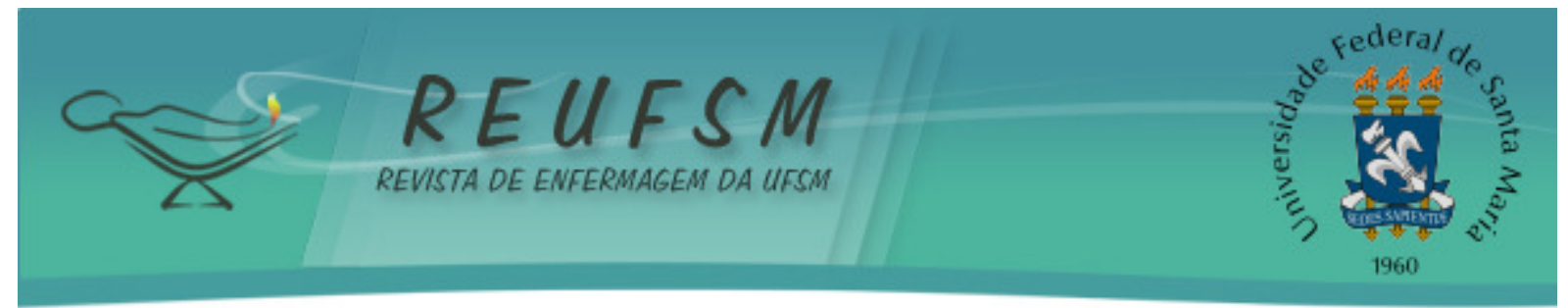

violentas para essa população vulnerável, nos aspectos físico e psicológico do desenvolvimento humano e no aspecto legal de autonomia para o cuidado de si. ${ }^{20}$

\section{CONSIDERAÇÕES FINAIS}

Apesar das intensas discussões atuais, a violência na escola deve impulsionar toda a sociedade a se inteirar desse panorama, pois esta não constitui somente em deveres às autoridades. O alerta aos profissionais de saúde é uma das questões importantes a serem estudadas, pois estes estão diretamente envolvidos neste problema. Mais que um atendimento ao trauma consequente ao fenômeno, são responsáveis por um serviço o qual abrange uma área geográfica com problemas diversos, exigindo a capacidade da escuta e do olhar qualificado. As condições psicológicas as quais os adolescentes se encontram, são outras características distintas e compreender as relações sociais conflituosas é, portanto, de suma importância.

Assim, abordar o tema da violência escolar em pesquisas possibilita uma nova perspectiva à Enfermagem, dimensionando outro universo de alternativas de enfrentamento da problemática. A efetividade das ações virá a partir do momento em que o enfermeiro passe a exercer plenamente sua cidadania, contribuindo para não remisssão dessa situação. Os enfermeiros, envolvidos em diferentes contextos (hospitais, ambulatórios, creches, escolas, unidades básicas de saúde) serão peças fundamentais para viabilização dos trabalhos de prevenção em diversas realidades, oportunizando assim, um trabalho que ampara o adolescente em prol da comunidade.

Discorrida essa abordagem entende-se que são muitos os que devem assumir responsabilidades. Talvez, o fator complicador para entendimento do que seja a violência na escola e suas consequências, esteja no fato dela compreender não simplesmente a um grupo de práticas objetivas.

De fato, a competência profissional legitima a ação do funcionário. Porém, a atribuição de sua participação na elaboração na proposta pedagógica, escassez de estudos eminentemente dotados do desempenho dos funcionários, bem como políticas de formação de trabalhadores da educação não-docente, confirmam o cunho da atenção voltada em sua maioria ao professor, coadjuvando todas as outras atribuições e necessidades da escola frente aquilo que é demandado ao funcionário. Isto posto, faz-se necessário o esforço de estudiosos e políticos, a fim de valorizar este trabalhador em educação e retratar de forma mais concisa todas as suas responsabilidades e deveres frente a óptica da violência escolar.

Ressalvas estas, que já fazem parte da percepção dos funcionários, pois para eles o cotidiano escolar vem sendo marcado pela violência que aparece na forma de segregação e exclusão ao outro. 0 foco dessas intervenções deve estar voltado para as habilidades sociais e acadêmicas: com busca de alternativas mais inclusivas, com imposição de regras concisas, estratégias de manejo do comportamento, análises contínuas das práticas e valores imputados no ambiente escolar e, por fim, atentar-se sempre que as diferenças sociais, quaisquer forem elas, jamais poderão produzir uma relação de poder que não permita a democratização.

Em virtude dessa magnitude a qual a violência na escola atinge e a repercussão sobre a saúde pública, esta configura um problema relevante e um desafio para os gestores do Sistema Único de Saúde (SUS). Frente a esse cenário, potencializar ações em rede que envolva profissionais de diferentes campos de atuação deve ser uma das mobilizações necessárias a colaborar com os compromissos morais e legais para com a sociedade. 


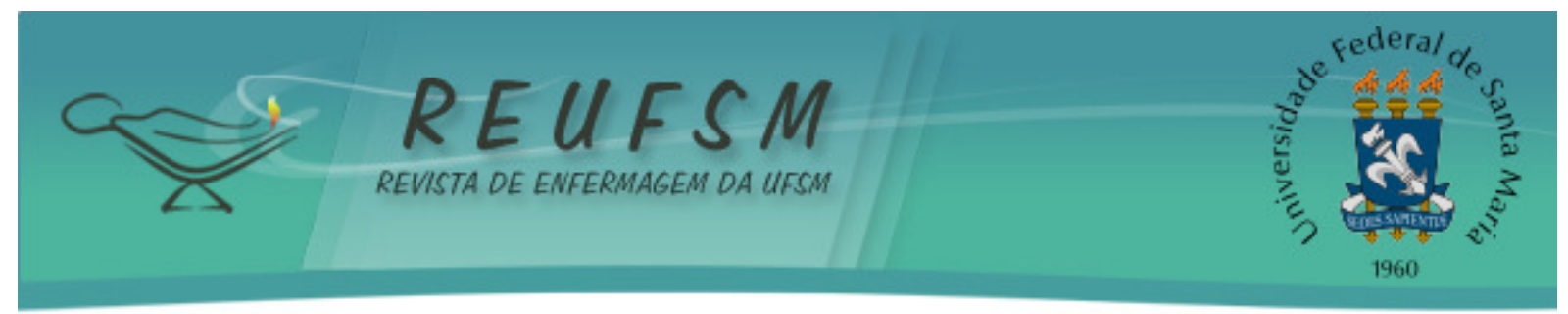

\section{REFERÊNCIAS}

1. Ministério da Saúde (BR). Secretaria de Políticas de Saúde. Violência intrafamiliar: Orientações para a prática em serviço. Brasília (DF): Ministério da Saúde; 2002.

2. Mascarenhas MDM, Malta DC, Silva MMA, Lima CM, Carvalho MGO, Oliveira VLA. Violência contra a criança: revelando o perfil dos atendimentos em serviços de emergência, Brasil, 2006 e 2007. Cad Saúde Pública. 2010;26(2):347-57.

3. Minayo MCS. Social violence from a public health perspective. Cad Saúde Pública, 1994;10 Supl 1:7-18.

4. Ministério da Saúde (BR). Secretaria de Atenção à Saúde. Atenção integral para mulheres e adolescentes em situação de violência doméstica e sexual: matriz pedagógica para formação de redes. Brasília (DF): Ministério da Saúde; 2011.

5. Pereira ACS, Williams LCA. Reflexões sobre o conceito de violência escolar e a busca por uma definição mais abrangente. Temas Psicol. 2010;18(1):45-55.

6. Ministério da Educação (BR). Secretaria de Educação Básica. Por uma política de valorização dos trabalhadores em educação: em cena, os funcionários de escola. Brasília (DF): Ministério da Educação. [internet] 2004 [acesso em 2012 ago 13]. Disponível em: http://portal.mec.gov.br/seb/arquivos/pdf/em_cena.pdf.

7. Abramovay M. Cotidiano das escolas: entre violências. Brasília (DF): UNESCO. [internet] 2006 [acesso em 2012 maio 20]. Disponível em:

http: / / unesdoc.unesco.org/images/0014/001452/145265por.pdf.

8. Mayer GR. Preventing antisocial behavior in the schools. J Appl Behav Anal. 1995;28(4):467-78.

9. Schiff $M$, Bargil B. Children with behavior problems: improving elementary school teachers' skills to keep these children in class. Child Youth Serv Rev. 2004;26(2): 207-34.

10. Ministério da Saúde (BR). Secretaria de Atenção à Saúde. Departamento de Atenção Básica. Saúde na escola. Brasília (DF): Ministério da Saúde; 2009.

11. Fontanella BJB, Ricas J, Turato ER. A amostragem por saturação em pesquisas qualitativas em saúde: contribuições teóricas. Cad Saúde Pública. 2008;24:17-27.

12. Bardin L. Análise de conteúdo. 4ªed. Lisboa: Edições 70; 2011. 280 p.

13. Ricas J, Donoso MTV. Aspectos históricos da educação no Brasil versus violência física na infância: reflexões. Rev Méd Minas Gerais. 2010;20(2):212-7.

14. Salles LMF, Silva JMAP. Diferenças, preconceitos e violência no âmbito escolar: algumas reflexões. Cadernos de Educação. FaE/PPGE/UFPel. 2008;(30):149-66.

15. Luizzi L, Rose TMS. Intervenções para a prevenção e redução de comportamentos agressivos e a formação de professores. Temas Psicol. 2010;18(1):57-69.

16. Lima RAP. Problematizando a violência no contexto atual: uma análise da abordagem da UNESCO. [monografia]. Londrina: Universidade Estadual de Londrina; 2009.

17. Gomide PIC. Abusa, negligência e parricídio: um estudo de caso. Temas Psicol. 2010;18(1): 219-30.

18. Donoso MV, Ricas J. A prática do castigo físico em crianças na visão dos perpetradores. Rev Enferm Cent-O Min. 2011;1(2):228-37. 


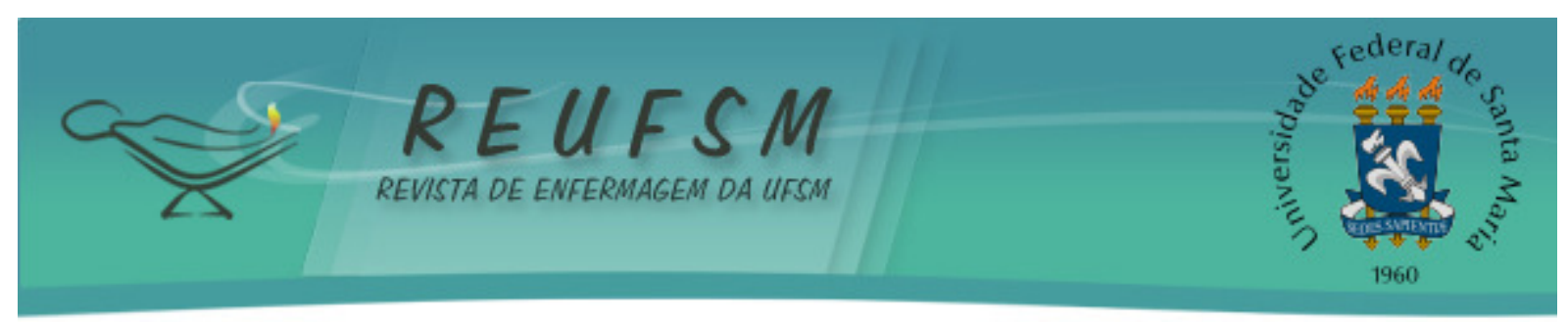

19. Organização Mundial da Saúde (OMS). Relatório mundial sobre violência e saúde. Genebra: Organização Mundial da Saúde. [internet] 2002 [acesso em 2012 maio 20]. Disponível em: http://www.opas.org.br/cedoc/hpp/ml03/0329.pdf

20. Netto Maia LLQG, Araújo A, Santos Júnior AS. Motivações para a violência no contexto escolar sob a óptica do adolescente. Rev Enferm UFSM. [internet] 2012 jan/abr [acesso em 2012 jul 25];2(1):20-31. Disponível em:

http://cascavel.ufsm.br/revistas/ojs2.2.2/index.php/reufsm/article/view/3760/3123.

Data de recebimento: 04/10/2012

Data de aceite: $17 / 12 / 2012$

Contato com autor responsável: Luciana Netto

Endereço: Rua Sebastião Gonçalves Coelho, 400 sala 301.4 Bloco D - Chanadour Divinópolis - MG - CEP 35.501-296

E-mail: luciananetto@ufsj.edu.br 